\title{
Bilateral Intramuscular Epidermal Cysts in the Erector Spinae
}

\author{
Rajesh Bhosle ${ }^{1}$ Sayan Das ${ }^{2}$ Ajoy Krishna Sarkar ${ }^{3}$ \\ ${ }^{1}$ Department of Neurosurgery, National Neurosciences Centre, \\ Calcutta, West Bengal, India \\ 2 Department of Radiology, Peerless Hospital, Calcutta, West Bengal, \\ India \\ ${ }^{3}$ Department of Internal Medicine, Peerless Hospital, Calcutta, West \\ Bengal, India
}

J Neurosci Rural Pract 2021;12:798-799.

A 65-year-old lady presented with history of chronic low back pain of several years' duration with no complaints of lower limb radiation, motor or sensory deficits, or sphincter involvement. There was no history of trauma. MRI (-Fig. 1) of her lumbar spine showed well-demarcated bilateral T1 hypointense and $\mathrm{T} 2$ hyperintense lesions inside the erector spinae muscles, extending from D12 to L2 levels. There was no evidence of any muscle contusion or edema. The lesions had no connection with the subcutaneous tissue or skin, and on examination too, the skin was normal. A CT scan
Prasad Krishnan ${ }^{10}$

Address for correspondence Prasad Krishnan, MS, MCh, Department of Neurosurgery, National Neurosciences Centre, 2nd Floor, Peerless Hospital Campus, 360, Panchasayar, Garia 700094, Kolkata, West Bengal, India (e-mail: prasad.krishnan@rediffmail.com).

of the lumbar region revealed the lesions to be hypodense in the center with peripheral isodensity (-Fig. 1). A Doppler ultrasound (USG) of the mass showed a "twinkling artefact" (-Fig. 1) with no definite vascular flow. A provisional diagnosis of an intramuscular epidermal cyst was made. The patient refused any intervention either in the form of an excision biopsy or USG-guided fine-needle aspiration cytology (FNAC) to confirm the diagnosis but agreed to follow-up periodically to evaluate for any increase in size.

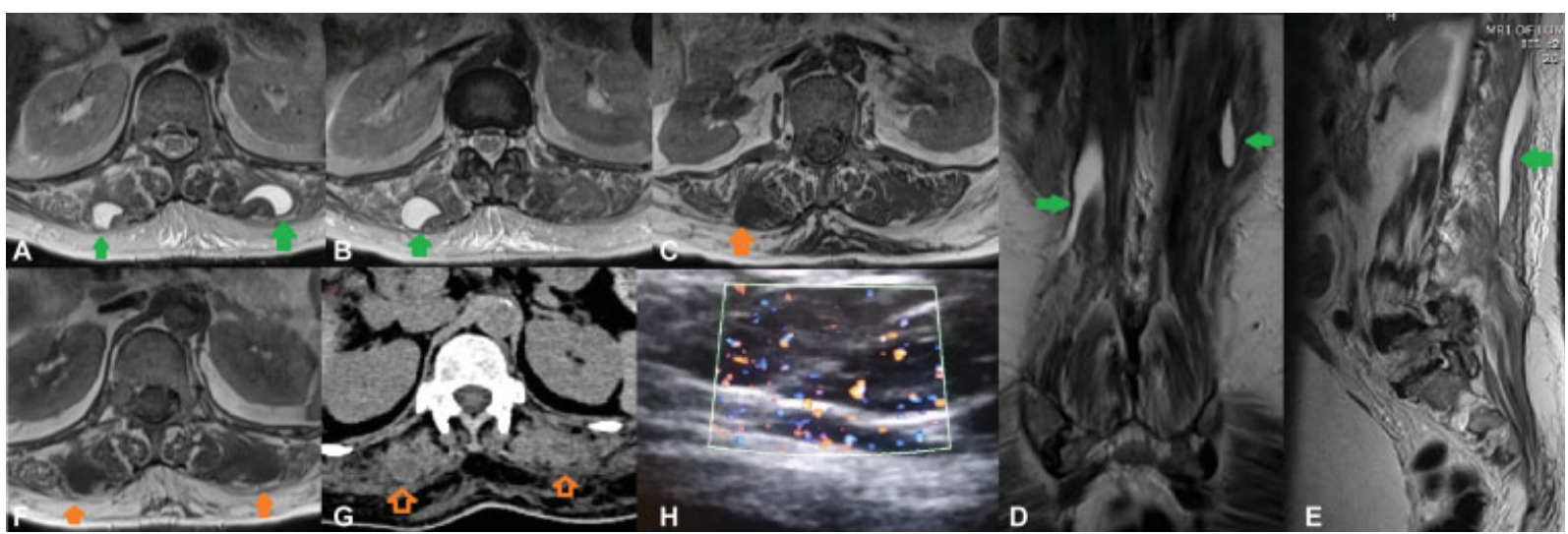

Fig. 1 T2-weighted axial MRI images (A, B) showing hyperintense well-demarcated lesions in bilateral erector spinae muscles (green arrows) with normal architecture of surrounding muscles; T1-weighted axial MRI (C) showing the lesion is hypointense (orange arrow); coronal T2weighted image (D) showing the lesions (green arrows); parasagittal T2-weighted image (E) showing the longitudinal extent of the lesion (green arrow); axial T1 MRI (F) and axial CT scans (G) showing the lesions (with open and closed orange arrows, respectively) but in the CT the center is more hypodense than the periphery and $(\mathrm{H})$ twinkling artifact seen on Doppler ultrasound of the lesion.

published online September 16, 2021
DOI https://doi.org/ $10.1055 / \mathrm{s}-0041-1735820$ ISSN 0976-3147. (c) 2021. Association for Helping Neurosurgical Sick People. All rights reserved.

This is an open access article published by Thieme under the terms of the Creative Commons Attribution-NonDerivative-NonCommercial-License, permitting copying and reproduction so long as the original work is given appropriate credit. Contents may not be used for commercial purposes, or adapted, remixed, transformed or built upon. (https://creativecommons.org/ licenses/by-nc-nd/4.0/)

Thieme Medical and Scientific Publishers Pvt. Ltd., A-12, 2nd Floor, Sector 2, Noida-201301 UP, India 
Intramuscular epidermal cysts are a rarity ${ }^{1}$ and when reported usually extend inward from their usual origin in the layers of the skin. There are very few instances of purely intramuscular epidermal cysts where no connection with the surface could be documented, ${ }^{2-4}$ and in such cases, the origin is speculated to be either from embedded epidermal elements driven in by trauma ${ }^{2}$ or from implantation of ectodermal cells during embryogenesis. ${ }^{4}$ In our case, the lesions were bilateral and fairly symmetric, and since there was no history of trauma, we speculate that they may have developed from anomalous cell nests that were sequestrated in the muscle during embryological development. We found only one previous case report in literature of epidermal cyst in the erector spinae ${ }^{3}$ which was unilateral.

This rare diagnosis may need to be kept in mind if a surgeon encounters a benign-looking cyst in the muscle in the absence of trauma. Mere absence of continuity with the skin cannot exclude the diagnosis, as these lesions can occur at any site and at any depth from the surface. ${ }^{4}$ Differential diagnosis includes intramuscular lipomas (which will be T1hyperintense on MRI and completely hypodense on CT scans), intramuscular hematomas (will have surrounding muscle contusion while old lesions may have calcification on CT scans), fibromas and soft-tissue sarcomas (will not be well-demarcated on imaging), and vascular malformations like hemangiomas (will show flow on doppler USG). The characteristic MRI and CT imaging features of a welldemarcated lesion with no muscle involvement and twinkling artifact on Doppler USG (due to the keratinaceous semisolid debris of the cyst $^{5}$ ) can clinch the diagnosis. Surgery is indicated in cases of diagnostic dilemmas, large and disfiguring lesions, or when the cyst is infected.

Conflict of Interest

None declared.

\section{References}

1 Low SF, Sridharan R, Ngiu CS. Giant epidermal cyst with intramuscular extension: a rare occurrence. BMJ Case Rep 2015;2015: bcr2013202534

2 Chatterjee PK, Chandra AB, Dastidar N. Epidermal cyst in sternomastoid muscle simulating a malignant growth. Indian J Otolaryngol 1976;28:86-87

3 Gill JH, Wui SH, Ko MJ, Park SW. An intramuscular epidermal cyst of erector spinae muscles: a case report. Surg Case Rep 2020;3:1-3

4 Suito M, Kitazawa T, Tsunekawa K, Shiba M, Ikeda T. Intertendinous epidermoid cyst of the forearm. Case Reports Plast Surg Hand Surg 2019;6(01):25-28

5 Ozan E, Atac GK, Gundogdu S. Twinkling artifact on color Doppler ultrasound: an advantage or a pitfall? J Med Ultrason (2001) 2016;43(03):361-371 